\title{
CHEMISTRY
}

\section{ВЛИЯНИЕ ТЕХНОЛОГИЧЕСКОГО РЕЖИМА УСТАНОВКИ ТЕРМИЧЕСКОГО ПИРОЛИЗА УГЛЕВОДОРОДОВ НА КАЧЕСТВЕННЫЙ СОСТАВ ТЯЖЁЛОЙ СМОЛЫ}

профессор, доктор технических наук, заведуюший лабораторией Садыгов Ф. М., доктор химических наук, главный научный сотрудник Магеррамова 3. Ю., доиент, кандидат химических наук, старший научный сотрудник Гаджсиев Г. Н., инженер Гасан-заде Г. Г., инженер Мамедова И. Г., инженер Меликова Э. Т.,

Азербайджан, Баку, Начиональная Академия Наук, Институт Катализа и Неоранической Химии им. М.Ф. Нагиева, лаборатория «Переработка побочных продуктов химической промышленности»

DOI: https://doi.org/ 10.31435/rsglobal_ws/31012019/6295

\section{ARTICLE INFO}

Received: 08 November 2018

Accepted: 20 January 2019

Published: 31 January 2019

\section{KEYWORDS}

technological regime, pyrolysis, heavy pitch, olefins,

ethylene, propylene, naphthalene, gasoline, aromatic hydrocarbons \begin{abstract}
The dependence of the yield and composition of the heavy pyrolysis resin on the initial hydrocarbon feedstock and the process conditions is investigated. The variation of technological parameters within certain limits leads to a change in the content of low molecular weight olefins in the gaseous pyrolysis products, as well as the qualitative and quantitative composition of by-product liquid products. As a result of the research, the optimum process conditions for the pyrolysis of straight-run gasoline were determined, which, with the maximum conversion of hydrocarbons to low-molecular-weight olefins, significantly increases the yield of heavy resin containing a wide fraction of naphthalene, biphenyl, indene and their alkyl derivatives. It is shown that when treating by-products containing valuable hydrocarbons as target products and combining the technological mode of pyrolysis and their composition, it is possible to achieve along with the maximum yield of low molecular weight olefins, a significant yield of heavy pyrolysis resin and qualitative changes in its composition.
\end{abstract}

Citation: Садыгов Ф. М., Магеррамова 3. Ю., Гаджиев Г. Н., Гасан-заде Г. Г., Мамедова И. Г., Меликова Э. Т. (2019) Vliyanie Tekhnologicheskogo Rezhima Ustanovki Termicheskogo Piroliza Uglevodorodov na Kachestvennyj Sostav Tyazhyoloj Smoly. World Science. 1(41), Vol.1. doi: 10.31435/rsglobal_ws/31012019/6295

Copyright: (C) 2019 Садыгов Ф. М., Магеррамова 3. Ю., Гаджиев Г. Н., Гасан-заде Г. Г., Мамедова И. Г., Меликова Э. Т. This is an open-access article distributed under the terms of the Creative Commons Attribution License (CC BY). The use, distribution or reproduction in other forums is permitted, provided the original author(s) or licensor are credited and that the original publication in this journal is cited, in accordance with accepted academic practice. No use, distribution or reproduction is permitted which does not comply with these terms.

На сегодняшний день основным способом получения низкомолекулярных олефинов - этилена и пропилена, остаётся процесс термического пиролиза углеводородного сырья. Пиролиз нефтяных фракций в печах трубчатого типа нашёл широкое применение в современной мировой практике [1].

В промышленных масштабах сырье, применяемое для пиролиза, в целом характеризуется разнообразием. Из научно-технической литературы известно, что традиционно основным сырьем процесса пиролиза являются: этан; пропан; бутаны, содержащиеся в попутных и в нефтезаводских газах; газовые бензины и бензины прямой перегонки нефти; рафинады каталитического риформинга, остающиеся после удаления ароматических углеводородов из катализата [2]. 
В связи с дефицитом и высокой стоимостью бензиновых фракций, в последнее время, в качестве сырья пиролиза применяют также средние и тяжёлые нефтяные фракции и даже сырую нефть [3].

Коксообразование и оптимальный выход целевых продуктов являются определяющими факторами при выборе технологического режима пиролиза [4].

Известно, что в зависимости от исходного сырья на установках пиролиза наряду с целевыми газообразными олефинами образуется значительное количество побочных жидких углеводородов, содержание которых может доходить до $40 \%$ от общей массы полученных продуктов. Лёгкая смола (пироконденсат), тяжёлая смола относятся к жидким побочным продуктам пиролиза и служат важным источником для получения не менее ценных, чем этилен и пропилен, соединений [5].

Пироконденсат, содержание которого достигает максимально 30\% от обшей массы продуктов, можно перерабатывать в ароматические углеводороды - бензол, толуол, ксилол, стирол, этилбензол, насыщенные и ненасыщенные циклические небензоидные соединения, нефтеполимерные смолы [6].

Тяжёлая смола, содержание которой максимально составляет $12 \%$, в зависимости от сырья, используемого в процессе, является источником бензольных - конденсированных и полициклических (в основном - нафталин, дифенил, инден и их алкилпроизводные) ароматических соединений. Этот побочный продукт пиролиза может быть использована для производства различных конструкционных углеродных материалов, таких как спекающие добавки, связующие, пропиточные и волокнообразующие пеки, позволяющие получать высокомодульные углеродные волокна, высокоактивный технический углерод, графит для атомных реакторов и игольчатый кокс, предназначенный для получения высококачественных графитовых электродов [7].

В настоящее время процесс пиролиза углеводородов обеспечивает сырьём многие нефтехимические процессы, и разработка методов усовершенствования процесса с целью увеличения выхода целевых и максимального использования побочных продуктов представляется актуальной задачей. На выход целевых и побочных продуктов процесса пиролиза оказывают влияние различные технологические параметры: температура, давление, качественный состав сырья, соотношение сырьё: водяной пар, время пребывания сырья в реакционной зоне [5].

Анализ доступной научно-технической литературы и интернет ресурсов показал, что в них отсутствуют современные фундаментальные исследования по изучению влияния технологических параметров процесса пиролиза углеводородного сырья на качественный и количественный состав побочных продуктов процесса.

Цель проведённого исследования - на основании производственных данных установки пиролиза углеводородов выявить оптимальное сочетание технологического режима пиролиза использованного сырья с качественным, и количественным составом полученных жидких продуктов, в частности тяжёлой смолы.

В ходе экспериментальных исследований, прежде всего, проводилось тщательное ознакомление с технологическим режимом процесса пиролиза на установке производства этилена. Варьирование технологических параметров в определённых пределах приводит к изменению содержания низкомолекулярных олефинов в газообразных продуктах пиролиза, а также качественного и количественного состава побочных жидких продуктов.

Технологический режим работы трубчатых печей на установке ЭП-300 (г. Сумгаит, Азербайджан) приводится ниже (табл. 1)

Таблица 1. Показатели технологический режима работы трубчатых печей на установке пиролиза углеводородного сырья

\begin{tabular}{|c|c|c|}
\hline \multirow{2}{*}{ Показатель } & \multicolumn{2}{|c|}{ Измерение } \\
\hline & Единица & Величина \\
\hline \multicolumn{3}{|c|}{ Температура продукта на выходе } \\
\hline - из печей & ${ }^{\circ} \mathrm{C}$ & $830-850$ \\
\hline - из закалочного аппарата & ${ }^{\circ} \mathrm{C}$ & $360-400$ \\
\hline \multicolumn{3}{|c|}{ Расход в печь } \\
\hline - углеводородного сырья - бензина & тон/час & $12,0-16,0$ \\
\hline - водяного пара & тон/час & $8,5-12,0$ \\
\hline \multicolumn{3}{|c|}{ Давление в нагреваемом трубопроводе } \\
\hline - на входе в пирозмеевик & МПа & $1,28-1,35$ \\
\hline - на выходе из пирозмеевика & МПа & $1,09-1,12$ \\
\hline Время прохождения сырья через пирозмеевик & сек. & $0,01-0,50$ \\
\hline
\end{tabular}


Известно, что на ЭП-300 (г. Сумгаит) в качестве сырья для пиролиза применяют четыре вида углеводородного сырья:

- прямогонный бензин;

- фракции $C_{3}-C_{4}$;

- этан + фракиии $C_{3}-C_{4}$;

- бензин $+C_{3}-C_{4}$.

Качественный и количественный составы исследуемых образцов углеводородного сырья пиролиза и побочного продукта процесса - тяжёлой смолы анализировали хроматографическим и хромато-массспектроскопическим методами:

- хроматограф Agilent 7820A (Agilent Technologies) - хроматографическая колонка HP5 ; длина колонки 30 м; внутренний диаметр 0,32 мм; толщина активной фазы на внутренней стенке $0,25 \mu \mathrm{M}$.

- хромато-масс-спектрометр Clarus 500 (Perkin-Elmer) - диапазон программированного нагревания $50-450^{\circ} \mathrm{C}$; расход форвакуумного насоса $3 \mathrm{~m}^{3} / \mathrm{q}$; расход турбомолекулярного насоса 259 л/с; диапазон сканирования масс 1-1200 а.е.м.; разрешение 1 а.е.м. по всему диапазону масс; максимальная скорость сканирования до 6500 а.е.м./с.

Предварительные исследования данных, полученных в течении 2017-го года на установке пиролиза ЭП-300, показали, что при использовании в качестве сырья фракици $C_{3}-C_{4}$ или смеси этан + фракция $C_{3}-C_{4}$ образуется относительно меньшее количество жидких побочных продуктов и в их составе массовая доля тяжёлой смолы может достигать $2 \%$. При применении в

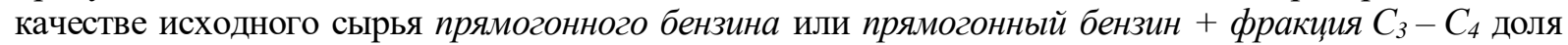
тяжёлой смолы в жидких побочных продуктах пиролиза значительно выше - более $11 \%$ (табл. 2).

Таблица 2. Количественные показатели по жидким побочным продуктам пиролиза и тяжёлой смоле

\begin{tabular}{|c|c|c|}
\hline \multirow{2}{*}{ сырьё для пиролиза } & \multicolumn{2}{|c|}{ содержание в продуктах пиролиза, масс. \% } \\
\cline { 2 - 3 } & $\begin{array}{c}\text { жидкие } \\
\text { углеводороды }\end{array}$ & $\begin{array}{c}\text { тяжёлая } \\
\text { смола }\end{array}$ \\
\hline $\begin{array}{c}\text { прямогонный } \\
\text { бензин }\end{array}$ & $32,84-39,56$ & $9,21-11,24$ \\
\hline $\begin{array}{c}\text { прямогонный бензин } \\
+ \text { фракиия } C_{3}-C_{4}\end{array}$ & $32,67-39,78$ & $8,38-9,45$ \\
\hline $\begin{array}{c}\text { фракция } \\
C_{3}-C_{4}\end{array}$ & $7,32-12,49$ & $0,77-1,99$ \\
\hline $\begin{array}{c}\text { этан } \\
+C_{3}-C_{4}\end{array}$ & $7,44-12,56$ & $0,32-1,77$ \\
\hline
\end{tabular}

Тяжёлая смола пиролиза представляет собой неоднородную смесь и содержит в своем составе (табл. 3):

- жидкие углеводороды;

- растворённые газы, которые представляют собой насыщенные и ненасыщенные углеводороды $\mathrm{C}_{1}-\mathrm{C}_{5}$ с нормальной и разветвлённой структурой;

- конденсат водяного пара;

- нерастворённые, неподвергающиеся идентификации частицы нефтеполимерных смол.

Таблица 3. Количественные показатели растворённых газов, конденсата водяного пара и нефтеполимерных смол в составе тяжёлой смолы в зависимости от качества сырья пиролиза

\begin{tabular}{|c|c|c|c|}
\hline \multirow{2}{*}{ сырьё для пиролиза } & \multicolumn{3}{|c|}{ содержание в тяжелой смоле, масс. \% } \\
\cline { 2 - 4 } & растворённые газы & конденсат водяного пара & нефте-полимерные смолы \\
\hline $\begin{array}{c}\text { прямогонный } \\
\text { бензин }\end{array}$ & $11,92-12,28$ & $2,41-3,18$ & $3,44-6,73$ \\
\hline $\begin{array}{c}\text { прямогонный бензин } \\
+ \text { фракиия } C_{3}-C_{4}\end{array}$ & $12,14-15,37$ & $2,56-7,43$ & $3,36-7,84$ \\
\hline $\begin{array}{c}\text { фракиия } \\
C_{3}-C_{4}\end{array}$ & $25,33-28,11$ & $3,25-5,85$ & $2,98-3,09$ \\
\hline $\begin{array}{c}\text { этан } \\
+C_{3}-C_{4}\end{array}$ & $18,7-19,98$ & $2,98-4,87$ & $3,16-3,32$ \\
\hline
\end{tabular}


Приведённые в таблице компоненты смеси тяжёлой смолы выделяются с помощью физических методов. После процедуры их отделения, очищенные образцы тяжёлой смолы подверглись анализу. В случае исходного сырья прямогонный бензин и прямогонный бензин + фракиия $C_{3}-C_{4}$, тяжёлая смола богата нафталином, дифенилом, инденом и их акилпроизводными. Также в составе жидких продуктов тяжёлой смолы имеется значительное количество циклических и ациклических, линейных и разветвлённых непредельных углеводородов, определённый набор которых тоже может представлять интерес для дальнейших исследований. Показана зависимость основных компонентов тяжёлой смолы от использованного в процессе пиролиза сырья (табл. 4).

Таблица 4. Зависимость основных компонентов тяжёлой смолы от применяемого углеводородного сырья

\begin{tabular}{|c|c|c|c|}
\hline \multirow{2}{*}{ сырьё для пиролиза } & \multicolumn{2}{|c|}{ основные углеводороды тяжёлой смолы, масс. \% } \\
\cline { 2 - 4 } & нафталины & дифенилы & индены \\
\hline $\begin{array}{c}\text { прямогонный } \\
\text { бензин }\end{array}$ & $21,42-37,04$ & $8,89-9,24$ & $4,93-5,13$ \\
\hline $\begin{array}{c}\text { прямогонный бензин } \\
+ \text { фракция } C_{3}-C_{4}\end{array}$ & $24,97-38,01$ & $8,45-9,73$ & $4,12-4,69$ \\
\hline $\begin{array}{c}\text { фракция } \\
C_{3}-C_{4}\end{array}$ & $10,89-11,33$ & $0,99-1,94$ & $0,08-0,11$ \\
\hline $\begin{array}{c}\text { этан } \\
+C_{3}-C_{4}\end{array}$ & $10,54-11,86$ & $1,33-1,67$ & $0,05-0,09$ \\
\hline
\end{tabular}

Сопоставление результатов хроматографического анализа образцов тяжёлой смолы, полученных в процессе пиролиза различных видов сырья, указывает на изменение состава тяжёлой смолы в зависимости от углеводородного исходного сырья. Это наглядно демонстрируется на примере основных компонентов - нафталинов, дифенилов, инденов. Если при использовании в процессе пиролиза в качестве сырья прямогонного бензина или смеси прямогонный бензин + рракция $C_{3}-C_{4}$ содержание этих углеводородов максимально в

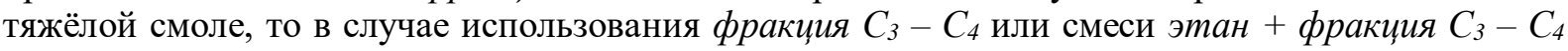
соответствующие показатели минимальны. Основные жидкие углеводороды тяжёлой смолы являются ценными веществами, сырьём для химической промышленности.

Нафталин применяется для синтеза фталевого ангидрида, тетралина, декалина, различных производных нафталина, которые используются для получения красителей и взрывчатых веществ, в медицине. Крупные монокристаллы применяются в качестве сцинтилляторов для регистрации ионизирующих излучений. Нафталины могут быть использованы для создания синтетических аналогов каннабиноидов.

Дифенил и его производные применяется как прекурсор в синтезе полихлорированных дифенилов, а также других соединений, используемых в качестве эмульгаторов, инсектицидов и красителей.

Индены применяются для получения кумароно-инденовых смол и ароматических углеводородных резин. Чистый инден используют в синтезе индана, а также для ряда производных, например, эфиров инден-1-карбоновой кислоты, применяемых в качестве акарицидов.

Для научных изысканий, в соответствии с поставленной целью, объектом исследований была выбрана тяжёлая смола процесса пиролиза, исходным сырьём которого служит прямогонный бензин. Известно, что в мировой практике прямогонный бензин применяется на нефтехимических объектах и предприятиях, как основное сырьё пиролиза для получения этилена и пропилена [8].

Прямогонным бензином или нафтой называют лёгкие бензиновые фракции, которые можно получить в результате переработки сырой нефти, газового конденсата, природного газа, попутного нефтяного газа и другого углеводородного сырья. Общее свойство прямогонных бензинов - низкое октановое число, которое меньше 40 , что не позволяет применять их в качестве автомобильного топлива. Только прямогонные бензины, полученные из бакинской нефти, имеют октановое число выше 65 и являются высококачественным сырьём для процессов пиролиза [9]. Качественный и количественный состав прямогонного бензина применяемого в качестве сырья на установке пиролиза (масс.\%), приведён ниже (табл. 5). 
Таблица 5. Состав прямогонного бензина - сырья для установки пиролиза

\begin{tabular}{|c|c|c|}
\hline № & углеводороды & массовая доля, \% \\
\hline 1 & н-бутан & $1,43-3,24$ \\
\hline 2 & 2-метилбутан & $6,77-8,37$ \\
\hline 3 & пентен & $0,67-0,81$ \\
\hline 4 & н-пентан & $8,97-10,59$ \\
\hline 5 & 2,2-диметилбутан & $0,56-0,78$ \\
\hline 6 & 2,3-диметилбутан & $2,33-4,13$ \\
\hline 7 & 2-метилпентан & $4,58-6,87$ \\
\hline 8 & 3-метилпентан & $3,48-4,80$ \\
\hline 9 & $H$-гексан & $8,94-10,49$ \\
\hline 10 & 2-метилгексан & $1,19-2,81$ \\
\hline 11 & метилциклопентан & $4,51-6,15$ \\
\hline 12 & 1,2-диметилциклопентан & $0,91-2,04$ \\
\hline 13 & бензол & $0,93-1,52$ \\
\hline 14 & циклогексан & $1,85-3,05$ \\
\hline 15 & 2,3-диметилгексан & $0,97-1,41$ \\
\hline 16 & 2,3-диметилпентан & $0,45-0,88$ \\
\hline 17 & 3-метилгексан & $0,98-1,83$ \\
\hline 18 & 2,2,4-триметилпентан & $0,38-0,75$ \\
\hline 19 & $\mu$-гептан & $4,29-5,44$ \\
\hline 20 & 2-метилгептан & $1,28-2,19$ \\
\hline 21 & метилциклогексан & $1,16-1,96$ \\
\hline 22 & 2,5-диметилгексан & $0,56-0,89$ \\
\hline 23 & 2,3,4-триметилпентан & $0,67-0,81$ \\
\hline 24 & толуол & $1,37-2,03$ \\
\hline 25 & 3-метилгептан & $1,56-1,65$ \\
\hline 26 & 1,2,3-триметилциклопентан & $0,39-0,63$ \\
\hline 27 & этилцикгексан & $0,49-0,67$ \\
\hline 28 & 1-метил-2-этилциклопентан & $1,97-2,38$ \\
\hline 29 & H-октан & $0,09-0,17$ \\
\hline 30 & изопропилциклопентан & $4,08-4,69$ \\
\hline 31 & 1,2-диметилциклогексан & $0,42-0,63$ \\
\hline 32 & 2-пропилциклопентан & $0,08-1,33$ \\
\hline 33 & 2,5-диметилгептан & $0,64-0,91$ \\
\hline 34 & этилбензол & $0,36-0,71$ \\
\hline 35 & 1,2,4-триметилциклогексан & $0,48-0,75$ \\
\hline 36 & 1,3-диметилбензол & $1,09-1,42$ \\
\hline 37 & 1,4-диметилбензол & $0,44-0,73$ \\
\hline 38 & 1,2,3-триметилциклогексан & $0,37-0,62$ \\
\hline 39 & 3-метилоктан & $0,69-0,98$ \\
\hline 40 & 1,2-диметилбензол & $0,65-0,81$ \\
\hline 41 & изобутилциклопентан & $1,27-1,56$ \\
\hline 42 & $H$-нонан & $3,98-4,34$ \\
\hline 43 & 1,3-диметил-5-этилбензол & $0,53-0,77$ \\
\hline 44 & 1,3,5-триметилбензол & $0,68-0,92$ \\
\hline 45 & 1-метил-4-изопропилбензол & $2,07-2,42$ \\
\hline 46 & 1,2,3,5-тетраметилбензол & $0,59-0,88$ \\
\hline
\end{tabular}

Очевидно, что в исходном сырье - прямогонном бензине отсутствуют компоненты тяжёлой смолы, которые являются основными объектами исследователей. Хроматографический анализ очищенной тяжёлой смолы, полученной пиролизом данного 
прямогонного бензина, показал, что в побочном продукте процесса в значительном количестве присутствуют интересующие потребителей вещества. Состав тяжёлой смолы, полученной при пиролизе бензина, (масс\%), приведён ниже (табл. 6).

Таблица 6. Углеводородный состав тяжёлой смолы - побочного продукта пиролиза прямогонного бензина

\begin{tabular}{|c|c|c|}
\hline № & углеводороды & массовая доля, $\%$ \\
\hline 1 & ксилолы & $1,46-1,78$ \\
\hline 2 & изопропилбензол & $2,44-2,69$ \\
\hline 3 & нафталин & $17,63-23,47$ \\
\hline 4 & метилнафталины & $5,05-5,48$ \\
\hline 5 & этилнафталины & $2,68-3,31$ \\
\hline 6 & диметилнафталины & $7,92-9,27$ \\
\hline 7 & индены & $4,93-5,31$ \\
\hline 8 & дифенилы & $8,42-9,54$ \\
\hline 9 & аценафтен & $2,82-3,34$ \\
\hline 10 & флуорен & $0,68-0,97$ \\
\hline 11 & фенантрен & $0,96-1,18$ \\
\hline 12 & антрацен & $1,28-1,56$ \\
\hline 13 & не идентифицированные & $4,67-4,94$ \\
\hline 14 & $\Sigma$ непредельные & $32,61-33,76$ \\
\hline
\end{tabular}

Анализ научной литературы показал наличие исследований по изучению влияния соотношения водяной пар: сырьё на выход целевых продуктов лишь для случая пиролиза фракция $\mathrm{C}_{3}-\mathrm{C}_{4}$ в присутствии катализатора [10]. При проведении исследований изучалось влияние соотношения количеств, взятого сырья и водяного пара на выход тяжёлой смолы и её качественный состав. Аналитические данные, полученные на установке ЭП-300, указывают на то, что процесс пиролиза углеводородного сырья проводится с применением значительных количеств водяного пара $(8,5-12,0$ т/ч) при соотношении сырья и водяного пара в пределах $1,0: 1,1-1,0: 1,6$. Эти технологические параметры оптимально приемлемы, так как большой расход водяного пара обеспечивает уменьшение скорости коксообразования, повышая тем самым продолжительность процесса пиролиза до 860 ч.

При изучении влияния времени хранения на состав и физико-химические свойства сырой (неочищенной) тяжёлой смолы пиролиза выявлено, что объект исследования неоднородная, гетерогенная система. При хранении такой тяжёлой смолы в стеклянной ёмкости в течение более года происходит расслоение на воду, углеводороды и тяжёлые смолистые соединения. Одновременно меняется качественный состав углеводородной части, но это не отражается на количестве нафталинов, дифенилов и инденов [11-12].

В существующих современных установках пиролиза выход и качество тяжелой смолы не регулируются. Если рассматривать смолу как побочный продукт процесса, нельзя добиться её стабильного состава и неизменных физико-химических свойств. Только при отношении к тяжёлой смоле как к дополнительному целевому продукту пиролиза, и, сочетая её качественный состав с технологическим режимом, при максимальном выходе основных продуктов процесса, можно достичь положительных результатов.

Таким образом, в результате проведённых исследовательских работ выявлен технологический режим пиролиза прямогонного бензина, позволяющий при оптимальной конверсии углеводородного сырья в низкомолекулярные олефины значительно увеличить выход тяжёлой смолы, содержащей широкую фракцию нафталинов, дифенилов, инденов.

Предложенный технологический режим работы трубчатых печей на установке ЭП-300 (табл. 7). 
Таблица 7. Показатели технологический режима работы трубчатых печей на установке пиролиза углеводородного сырья

\begin{tabular}{|c|c|c|}
\hline \multirow{2}{*}{ Показатель } & \multicolumn{2}{|c|}{ Измерение } \\
\hline & Единица & Величина \\
\hline \multicolumn{3}{|c|}{ Температура продукта на выходе } \\
\hline - из печей & ${ }^{\circ} \mathrm{C}$ & $845-850$ \\
\hline - из закалочного аппарата & ${ }^{\circ} \mathrm{C}$ & $360-380$ \\
\hline \multicolumn{3}{|l|}{ Расход в печь } \\
\hline - углеводородного сырья - бензина & тон/час & $15-16$ \\
\hline - водяного пара & тон/час & $10-12$ \\
\hline \multicolumn{3}{|c|}{ Давление в нагреваемом трубопроводе } \\
\hline - на входе в пирозмеевик & МПа & $1,32-1,35$ \\
\hline - на выходе из пирозмеевика & МПа & $1,11-1,12$ \\
\hline Время прохождения сырья через пирозмеевик & сек. & $0,20-0,50$ \\
\hline
\end{tabular}

В ходе исследований своё подтверждение нашло утверждение, что углеводородный состав, физико-химические свойства тяжёлой смолы пиролиза на промышленной установке изменяются в зависимости от сырья, технологического режима процесса, расхода перегретого водяного пара. Анализы показали, что состав побочных продуктов пиролиза изменяется даже при переработке одного вида сырья. В этом случае доминирующим фактором процесса пиролиза является технологический режим.

\section{ЛИТЕРАТУРА}

1. Литвинцев И.Ю. Пиролиз // Химический Журнал (The Chemical Journal). — 2006, № 5, c. 42-46.

2. Жагфаров Ф.Г., Гуськов П.О., Лапидус А.Л. Тенденции переработки газового углеводородного сырья в процессе пиролиза // Газохимия. - 2011, № 3-4 (19-20), с. 26-31.

3. Пат. 2002126609А РФ, 2004. А. Дж. Баумгартнер, Пуи-Юэн Джеффри Чан, Денни Юк-Кван Нган. Пиролиз сырой нефти и фракций сырой нефти, содержащих пек.

4. Андреева М.М. Кокс образование при пиролизе угледоводородного сырья // Вестник Казанского университета. - 2014, т. 17, № 2, с. 279-280.

5. Солодова Н.Л., Абдуллин А.И. Пиролиз углеводородного сырья. - Казань: Издательство КНИТУ, 2007,239 c.

6. Садыгов Ф.М., Магеррамова З.Ю., Гаджиев Г.Н., Джахандаров Ш.Дж., Мамедова И.Г. Рациональная переработка пироконденсата - побочного продукта производство этилена // WORLD SCIENCE Dubai: 2018, vol.2, № 2(30), p. 52-55

7. Думский Ю.В., Чередникова Г.Ф., Думский С.Ю. Новые процессы квалифицированного использования жидких побочных продуктов пиролиза углеводородного сырья // Известия Волгоградского государственного технического университета. — 2014, № 1, с. 80-82.

8. Салахов И.И. Пиролиз прямогонного бензина с добавлением водорода в производстве низших олефинов. Дисс. канд. техн. наук. - Казан: Казанский Государственный Технологический университет. - 2005, $171 \mathrm{c}$.

9. Магеррамов А.М., Ахмедова Р.А., Ахмедова Н.Ф. Нефтехимия и нефтепереработка. — Баку: «Бакы Университети». - 2009, 660 с.

10. Лаврентьева Т.А., Каратун О.Н. Влияние соотношения водяной пар: сырье на выход целевых продуктов процесса пиролиза пропан-бутановой фракции в присутствии пентасилсодержащих катализаторов // Вестник Астраханского государственного технического университета. - 2009, № 1 (48), c. $42-46$.

11. Садыгов Ф.М., Магеррамова 3.Ю., Гаджиев Г.Н., Гейдарлы Н.И., Садыгова Н.С., Гахраманов Г.С. Переработка тяжелой смолы пиролиза с целью решения экологических проблем // Материалы Республиканской научной конференции посвященной 80-летнему юбилею Института катализа и неорганической химии. - Баку, 2016, с. 452-453.

12. Садыгов Ф.М., Магеррамова 3.Ю., Гаджиев Г.Н., Гусейнов И.А., Гейдарлы Н.И., Гасан-заде Г.Г. Исследование путей извлечения нафталина из тяжелой смолы пиролиза // Тезисы Бакинской Международной Мамедалиевской конференции. — Баку, 2016, с. 137. 